\title{
Allergic Fungal Rhinosinusitis
}

\author{
Ashok K Gupta, Nishit Shah, Mohan Kameswaran, Davinder Rai, TN Janakiram, Hemant Chopra, Ravi Nayar \\ Arvind Soni, NK Mohindroo, C Madhu Sudana Rao, Sandeep Bansal, KR Meghnadh, Neelam Vaid \\ Hetal Marfatia Patel, Sanjay Sood, Sunita Kanojia, Kshitij Charaya, SC Pandhi, SBS Mann
}

\begin{abstract}
Allergic fungal rhinosinusitis (AFRS) has always remained a topic of discussion at all rhinology meets. Despite so much of literature available, the nature of this disease, its diagnosis, pathogenesis, classification and appropriate management continue to generate debate and controversy even after three decades of research and investigation. AFRS is an endemic disease in North and South India. In spite of this, there has been no optimal management protocol for this disease being followed in India yet. To overcome this, a national panel was conducted on AFRS at the E NT Surgical Update 2011, held at P ostgraduate Institute of Medical Education and R esearch, Chandigarh with experts from all over the country so that a consensus can be achieved regarding the workup and management of AFRS.
\end{abstract}

Keywords: R hinosinusitis, Allergic fungal sinusitis, Management protocol.

How to cite this article: Gupta AK, Shah N, Kameswaran M, Rai D, J anakiram TN, Chopra H, Nayar R, Soni A, Mohindroo NK, Rao CMS, Bansal S, Meghnadh KR, Vaid N, Patel HM, Sood S, Kanojia S, Charaya K, Pandhi SC, Mann SBS. Allergic Fungal Rhinosinusitis. Clin Rhinol An Int J 2012;5(2): 72-86.

\section{Source of support $\mathrm{Nil}$}

Conflict of interest: None declared

\section{INTRODUCTION}

Allergic fungal rhinosinusitis (AFRS) was recognized for the first time in 1976 when in some patients thick, dark, inspissated mucus was noticed filling the paranasal sinuses, similar both grossly and microscopically to that seen in the bronchial passages of patients with allergic bronchopulmonary aspergillosis (A BPA) ${ }^{1-3}$ It is invariably associated with nasal polyposis and the presence of allergic fungal mucin. Allergic fungal mucin is thick and tenacious macroscopically having a brown or greenish black color. This mucus consists of onion-skin laminations of necrotic eosinophils in various stages of degeneration, occasional small hexagonal crystals of lysophospholipase (CharcotLeyden crystals) and scanty fungal hyphae on histology. It is a nontissue invasive fungal process, representing an allergic/hypersensitivity response to the presence of extramucosal fungi within the sinus cavity in which a strong IgE-mediated hypersensitivity to fungal elements drives the inflammatory process. Aspergillus and the dematiaceous fungi are most commonly found in AFRS mucus. ${ }^{4-6}$ The preferred terminology for this condition is now 'allergic fungal rhinosinusitis' or AFRS though once it was called 'allergic' Aspergillus sinusitis. There are a lot of variations seen in patients with similar clinical presentation as AFRS. It has been noted that in some cases, the eosinophilic mucin from the sinuses does not have identifiable fungal elements. ${ }^{6,7}$ Ferguson described an A FRS-like condition with slightly different clinical features and proposed the term 'eosinophilic mucin rhinosinusitis' (EM RS) to describe cases in which fungus was not identified histologically. ${ }^{8}$

On the other hand some patients with clinical features of AFRS may have demonstrable fungus within their eosinophilic mucin, but no allergy. ${ }^{9}$ There have been cases isolated with no allergy; no fungi in mucin but still have eosinophilic mucin. Ponikau et al postulated that most, if not all, CRS was a hypersensitivity response to fungi and that fungi could be universally cultured from nasal secretions also further clouded the distinction between AFRS and A FRS-like CRS. ${ }^{10}$ The nature of this disease, its diagnosis, pathogenesis, classification and appropriate management continue to generate debate and controversy even after three decades of research and investigation.

\section{PATHOGENESIS}

A FRS was described as distinct clinical entity by M illar in $1981^{3}$ and Katzenstein ${ }^{2}$ in 1983 characterized by atopy, sinonasal polyposis and the presence of allergic mucin. It was thought that the fungus in the sinuses would have potential for tissue invasion so extensive surgical debridement followed by the use of systemic antifungal agents was the treatment of choice those days. The realization that AFRS may represent an immunological response to presentation of a fungal antigen within a susceptible host leads to the discontinuation of such treatment. A s in A BPA, an atopic host is exposed to fungi through normal nasal respiration, thus providing an initial antigenic stimulus. Gel and Coombs type I (IgE) and III (immune complex) mediated reactions trigger an intense eosinophilic inflammatory response. Any anatomic obstruction, such as septal deviation or turbinate hypertrophy, accentuates the already inflamed mucosa which in turn leads to obstruction of sinus ostia resulting in stasis of mucus within the sinuses. This, in turn, creates an ideal environment for further proliferation of the fungus, thus increasing the antigenic exposure. This sets up a vicious cycle and produces a lot of allergic mucin.

This immunological aspect in the pathogenesis was supported by studies by Manning and Holman. ${ }^{11}$ In their 
first study on eight patients, culture-positive bipolaris A F RS were prospectively compared with 10 controls with chronic rhinosinusitis. All eight patients with AFRS had positive skin test reactions to bipolaris antigen, as w ell as significant levels of bipolaris specific IgE and IgG by in vitro testing. Eight of the 10 control demonstrated negative results to both skin and serologic testing, suggesting that the presence of allergy to fungus as being important in the pathogenesis of AFRS.

In another study by them ${ }^{11}$ sinus mucosal specimens from 14 patients with AFRS were compared with those from 10 controls with chronic rhinosinusitis. Immunohistochemical analysis for eosinophilic mediators (major basic protein and eosinophilic derived neurotoxin) and a neutrophil-derived mediator (neutrophil elastase) was performed to compare the underlying inflammatory processes within each cohort. Inflammatory mediators derived from eosinophils predominated over neutrophilderived mediators in the AFRS group, whereas significant differences were not present within the control group. The relative predominance of eosinophil-derived inflammatory mediators as compared to neutrophil-derived inflammatory mediators further support the association between noninfectious (i.e. immunologically mediated) inflammation and A FRS, and helps to differentiate this di sease from other forms of chronic rhinosinusitis. This is further supported by the study by Stewart and Hunsaker ${ }^{12}$ in which they analyzed fungal-specific serum IgE and IgG levels in nonatopic controls, allergic rhinitis patients, non-AFRS polyp patients, AFRS-like patients and AFRS patients. It was found that in patients with AFRS and AFRS-like group there was elevated serum levels of I $\mathrm{gE}$ and IgG to multiple fungi.

The concept of eosinophilic activation associated with AFRS was further supported by Feger et al $^{13}$ who studied eosinophilic cationic protein (ECP) levels in the serum and mucin of patients with AFRS. No differences in serum ECP were detected between patients with AFRS and controls, but ECP levels were significantly higher in mucin from patients with AFRS as compared to controls.

These studies by $M$ anning et $\mathrm{al}^{11}$ and Feger et al ${ }^{13}$ while supporting that AFRS represents an immunologicallymediated disorder rather than an early stage of invasive fungal disease fuelled further speculation regarding the pathophysiology of AFRS.

In 1999 a 'unifying hypothesis' of CRS was proposed by Ponikau et al. ${ }^{10}$ They used a specially designed culture technique, and found that $93 \%$ of 101 consecutive patients with CRS demonstrated the presence of fungi obtained from nasal lavage and surgically obtained specimen. In contrast to prior AFRS studies, conventional IgE-mediated allergy to fungi was not consistently observed. It was therefore proposed that virtually all cases of chronic rhinosinusitis were associated with sensitization to colonizing fungi. It was further suggested that the term 'allergic fungal rhinosinusitis' be replaced with 'eosinophilic fungal rhinosinusitis' (EFRS). ${ }^{10}$ These findings have led to their belief that IgE-mediated inflammation is not crucial to the development of AFRS, and that eosinophilic chemotaxis and activation may result from a $\mathrm{T}$ Iymphocyte-mediated inflammatory cascade. One potential problem with the common etiology that was proposed by the authors was the fact that fungi were al so observed in $100 \%$ of normal control subjects.

In a study on humoral immune response in patients with EMCRS including AFRS Pant et $\mathrm{al}^{9}$ found that patients with AFRS had increases in fungal-specific IgE and total IgE but these were no different from a control group with allergic rhinitis. Though there was a poor correlation between fungal species present in the eosinophilic mucin of A FRS patients and the specific fungal allergy (42\%) but elevated fungal-specific IgG3 was a distinguishing serologic feature that separated EM CRS and AFRS patients from those with fungal allergic rhinitis and other forms of CRS. M oreover, serum IgE levels could be used to distinguish EM CRS from A FRS. A nother clinically important distinguishing feature of AFRS is type 1 hypersensitivity. Therefore, type 1 hypersensitivity to fungal antigens, as assessed by specific allergy tests, helps to distinguish AFRS from other forms of EMCRS and has implications for treatment.

Recently in 2009 Luong et al $^{14}$ found that peripheral blood mononuclear cells from A FRS patients are stimulated by fungal antigens to secrete TH2-type cytokines.

In spite of all these studies supporting humoral immune factors, the underlying pathophysiology in AFRS remains steeped in controversy. Although it appears clear that the eosinophil plays an important role in the development of both AFRS and some forms of chronic rhinosinusitis, the factors that ultimately trigger eosinophilic inflammation remain in question.

In summary, it can be said that initiation of the inflammatory reaction leading to AFRS is a multifactorial event, governed by IgE-mediated sensitivity (atopy), humoral expression, exposure to specific fungi and aberration of local mucosal defence mechanisms.

\section{Epidemiology and Clinical Presentation}

It is estimated that approximately 5 to $10 \%$ of those patients with chronic rhinosinusitis actually carry a diagnosis of AFRS. $^{2}$ It is most common among adolescents and young adults (mean age; 21.9 year). ${ }^{11}$ The incidence of AFRS 
appears to be impacted by geographic factors. On review of literature it was found that the majority of sites reported cases of AFRS to be located in temperate regions with relatively high humidity. In U nited States most cases are found in the southern central region of the country along the Mississippi basin. ${ }^{15}$ In India, fungal sinusitis is maximally reported from $\mathrm{N}$ orth India ${ }^{16-18}$ and South India. ${ }^{19}$

Initially, Aspergillus was believed to be the causative organism in AFRS, but dematiaceous fungi were most commonly found in AFRS mucus, in different studies conducted in the United States. ${ }^{20,21}$ In other parts of the world, Aspergillus is still found to be a common isolate in cases of AFRS and nonallergic eosinophilic fungal sinusitis. ${ }^{17,22}$ Identification of the specific fungal organism is important only for making a diagnosis, it does not have any prognostic value nor does it make any difference in the planning of the treatment protocol.

A FRS occurs in adolescents and young adults who often have asthma that is exacerbated by their sinusitis. All patients are immunocompetent and have a strong history of atopy. A II have nasal polyps and chronic sinusitis. There is no increased aspirin sensitivity despite the association with asthma and nasal polyps.

The development of nasal airway obstruction is gradual and the patient is unaw are of its presence and presents only when there is complete nasal obstruction or may develop more serious symptoms like headaches and visual disturbances. Facial dysmorphism if present is also often so slow that its identification escapes notice of the patient and family members. The slow accumulation of allergic fungal mucin imparts unique and predictable characteristics to the disease. Allergic fungal mucin is sequestered within involve paranasal sinus cavities. As its quantity increases, the involved paranasal sinus begins to resemble and behave in a way consistent with a mucocele (sometimes referred to as a fungal mucocele). ${ }^{23} \mathrm{~W}$ ith time, bony remodeling and decalcification may occur, causing the disease to mimic 'invasion' into adjacent anatomic spaces. The location of bone destruction seems to be determined simply by the location of the disease, and this destruction often gives rise to exophthalmos, facial dysmorphia or intracranial extension without tissue invasion. ${ }^{24}$

In cases of allergic fungal sinusitis, the mechanism of vision loss has thus, far been assumed to be secondary to direct compression or direct inflammation of the optic nerve. Gupta et al hypothesized that there may be aberrant anatomical pathways present in the region of the optic canal could have been responsible for direct inflammation of the nerve in the absence of obvious bony erosion apart from mechanical compression of the optic nerve, a local immunological reaction to fungal antigens might be responsible for the visual loss seen in allergic fungal sinusitis. ${ }^{25}$

\section{Diagnostic Criteria}

A patient with AFRS classically is a young (mean age is 22 years), immunocompetent patient with unilateral or asymmetric involvement of the paranasal sinuses, a history of atopy, nasal casts and polyposis, and a lack of significant pain. ${ }^{11} \mathrm{~N}$ asal casts are green to black rubbery formed elements made of allergic mucin. The presentation may be dramatic, with a significant number of patients presenting with proptosis, telecanthus or gross facial dysmorphia. ${ }^{17}$ The diagnosis for A FRS is usually derived from the clinical, radiological, microbiological and histopathological information combined together. There has been a lot of debate regarding the diagnostic criteria for A FRS.

A number of different attempts at establishment of diagnostic criteria have been proposed, most of which focus upon some combination of the radiologic, immunologic, clinical and histologic manifestations of the disease. A Ilphin et al ${ }^{6}$ felt that the combination of opacified paranasal sinuses on radiography, characteristic histologic findings of allergic mucin, and laboratory evidence of allergy was sufficient to differentiate A FRS from other forms of rhinosinusitis. L oury and Schaefer ${ }^{26}$ proposed a more specific set of diagnostic criteria, which included eosinophilia, immediate skin reactivity or serum IgE antibodies to fungal antigen, elevated total IgE level, nasal mucosal edema or polyposis, histopathologic findings of allergic mucin containing noninvasive fungal hyphae, and characteristic radiological findings.

In 1994, Bent and Kuhn published their diagnostic criteria centered on the histologic, radiographic and immunologic characteristics of the disease ${ }^{27}$ and they still remain the standard and most widely accepted worldwide.

A ccording to B ent and $\mathrm{K}$ uhn patients must meet all the major criteria for diagnosis, while the minor criteria support the diagnosis. The major criteria include a history of type I hypersensitivity by history, skin testing or in vitro testing; nasal polyposis; characteristic computed tomography (CT) scan findings; the presence of eosinophilic mucin without invasion and a positive fungal stain of sinus contents removed at the time of surgery. The minor criteria include a history of asthma, unilateral predominance of disease, radiographic evidence of bone erosion, fungal cultures, presence of Charcot-L eyden crystals in surgical specimens and serum eosinophilia (Table 1).

\section{Table 1: Bent and Kuhn's diagnostic criteria}

\begin{tabular}{ll} 
Major & Minor \\
\hline Type I hypersensitivity & Asthma \\
Nasal polyposis & Unilateral disease \\
Characteristic CT findings & Bone erosion \\
Eosinophilic mucin without invasion & Fungal cultures \\
Positive fungal stain & Charcot-Leyden crystals \\
& Serum eosinophilia \\
\hline
\end{tabular}




\section{Histology of Allergic Fungal Mucin}

Microscopic picture on hematoxylin and eosin $(H \& E)$ staining of mucin is an important diagnostic tool and would show typical inflammatory infiltrate composed of eosinophils, eosinophilic breakdown products or CharcotLeyden crystals, lymphocytes and plasma cells. ${ }^{27}$ The mucosa will be hypertrophic and hyperplastic but should not have evidence of necrosis, giant cells, granulomas or invasion into surrounding structures. It is important to note that examination of the unique allergic fungal mucin itself, and not the surrounding mucosa, is the most reliable indicator of disease. Grossly, this thick, highly viscous, variably colored mucin has been described as being similar to peanut butter or axle grease. ${ }^{28} \mathrm{H} \& \mathrm{E}$ staining accentuates the mucin and cellular components of allergic fungal mucin. Using this stain, background mucin will often take on a chondroid appearance, whereas eosinophils and CharcotLeyden crystals are heavily stained and become easily detected. Fungi fail to stain with $H \& E$, however, and may be implicated only by their resulting negative image against an otherwise stained background. Given that fungal hyphae are frequently rare, scattered, and fragmented within allergic mucin, identification is extremely difficult unless specific histological stains are used. F ungal elements are recognized for their unique ability to absorb silver. This property is the basis for various silver stains, such as G rocott's or Gomori's methenamine silver (GMS) stain, which turn fungi black or dark brown. The use of a fungal stain complements the findings of initial $H \& E$ stain and is extremely important in the identification of fungi. ${ }^{28}$

Fungi commonly identified in the electron microscopy are from the dematiaceous family and Aspergillus species, ${ }^{6}$ Dematiaceous fungi include the genera Alternaria, Bipolaris, Cladosporium, Curvularia, D rechslera and Helminthosporium. These fungi are darkly pigmented due to dihydroxynaphthalene melanin in the cell walls of the hyphae or conidia.

Fungal hyphae do not invade tissue: The presence of fungal tissue invasion has been considered incompatible with a diagnosis if A FRS. M any patients with polypoid CRS and eosinophilic mucin lack other important clinical characteristics of AFRS: Demonstrable fungi and fungal allergy. These patients should not be classified as having AFRS. In a study Dhiwakar et al ${ }^{18}$ pointed out that the combination of nasal polyps, CT scan hyperattenuation and elevated titers of anti-Aspergillus IgE have high predictive value for AFRS, though considered in isolation they are not specific. There is a lot of overlap that exists between AFRS, EM CRS and CRS from other causes, but B ent and $\mathrm{K}$ uhn ${ }^{27}$ criteria can still distinguish between these.

\section{Immunologic Findings}

The original reports describing AFS focused on the fungus Aspergillus. M iller et al ${ }^{3}$ described immediate cutaneous reactivity to Aspergillus fumigatus antigen in all five patients in their original case series. $K$ atzenstein et $a^{2}$ found specific $\mathrm{IgE}$ and immunoglobulin $\mathrm{G}(\mathrm{IgG})$ to Aspergillus in their series. The total IgE level has served as a useful tool to follow the clinical activity of allergic bronchopulmonary aspergillosis. B ased on similar IgE behavior associated with recurrence of AFRS, total IgE levels have been proposed as a useful indicator of AFRS clinical activity. Total IgE values are generally elevated in AFRS, often to more than $1,000 \mathrm{U} / \mathrm{ml}^{13,29,30}$ elevated in all patients with AFRS and corresponded with the results of fungal cultures. In contrast, levels of fungal-specific IgE were not elevated within the control group of patients with chronic rhinosinusitis. Moreover, patients with AFRS appear to demonstrate a broad sensitivity to a number of fungal and nonfungal antigens. $M$ abry et al have reported their experience, which indicates that patients with AFRS are allergic to multiple fungal antigens, as well as many typical nonfungal antigen. ${ }^{31}$ Patients with A F RS generally demonstrate positive skin test and in vitro (RAST) responses for both to fungal and nonfungal antigens. $M$ anning et al first demonstrated the sensitivity of RAST, who compared 16 patients with histologically confirmed AFRS with a control group with chronic rhinosinusitis. Levels of fungal-specific IgE were uniformly elevated in patients with A FRS and corresponded with the results of fungal cultures. ${ }^{32}$

$M$ orpeth et $\mathrm{al}^{33}$ in their review on AFS literature noted the following immunologic findings: $48 \%$ with positive skin tests to fungi, $44 \%$ with elevated total $\mathrm{IgE}, 40 \%$ with peripheral eosinophilia, 33\% with elevated specific IgG, and $28 \%$ with serum precipitins to fungal antigens. Schubert and Goetz found that $67 \%$ of their patients had an elevated total IgE (greater than $199 \mathrm{IU} / \mathrm{ml}$ ). The mean total IgE for their patients was $668 \mathrm{IU} / \mathrm{ml}$. A II patients have positive skin tests for aeroallergens with specific IgE to their presumably causal mold and two-thirds of patients having elevated specific IgG to molds. ${ }^{30}$

N onspecific inflammatory findings in the surgical debris removed from AFS patients include elevated levels of eosinophilic cationic protein and major basic protein. This indicates eosinophilic degranulation.

Ponikau et $\mathrm{al}^{10}$ postulated that there is a nonspecific eosinophilic response in these patients to the presence of fungal elements in the nose and sinuses. We need further studies to confirm these findings, because if the inflammatory process in AFS is actually driven mostly by a nonspecific eosinophilic reaction rather than by specific IgE, then steroids will continue to be the primary medical therapy 
and immunotherapy with fungal antigen extracts will have no role. If the etiology of AFS is a specific IgE-mediated immunologic response then appropriate immunotherapy may be initiated and would be efficacious.

\section{Fungal Culture}

Fungal cultures provide only supportive evidence helpful in the diagnosis and subsequent treatment of A FRS, but must be interpreted with caution and the diagnosis of AFRS is not established or eliminated based on the results of these cultures as yield is variable from 64 to $100 \% \cdot{ }^{19} \mathrm{~A}$ diagnosis of A FRS in the presence of a negative fungal culture is possible but there may be a situation when a positive fungal culture fails to confirm the diagnosis of AFRS, because it may merely represent the presence of saprophytic fungal growth.

A panel of international experts in 2004 convened to establish working diagnosis for chronic rhinosinusitis which included A FRS. The impact of IgE-mediated sensitivity to fungus in AFRS was acknowledged by the panel and they proposed diagnostic criteria based upon the combination of histologic, immunologic, clinical and radiologic factors ${ }^{34}$ (Table 2).

\section{RADIOLOGICAL FEATURES}

AFRS has characteristic features on $C T$ scan or MRI considered extremely important for diagnosis. CT scan shows multiple opacified sinuses with central hyperattenuation, sinus mucocele formation and erosion bone. Ghegan et al ${ }^{35}$ showed that $56 \%$ of AFRS cases presented with radiographic evidence of skull base erosion or intraorbital extension, whereas similar findings were only noticed in $5 \%$ of other cases of chronic sinusitis. Zinreich

\begin{tabular}{|c|c|}
\hline \multicolumn{2}{|c|}{ Table 2: Diagnostic criteria for AFRS (2004) } \\
\hline Symptoms & $\begin{array}{l}\text { Requires } \geq \text { one of the following: } \\
\text { - Anterior and/or posterior nasal drainage } \\
\text { - Nasal obstruction } \\
\text { - Decreased sense of smell } \\
\text { - Facial pain-pressure-fullness }\end{array}$ \\
\hline Objective findings & $\begin{array}{l}\text { Requires all of the following: } \\
\text { - Presence of allergic mucin (fungal } \\
\text { hyphae with degranulating eosinophils on } \\
\text { histopathology) } \\
\text { - Evidence of fungal-specific IgE } \\
\text { - No histologic evidence of invasive fungal } \\
\text { disease }\end{array}$ \\
\hline Radiologic findings & $\begin{array}{l}\text { Highly recommended: } \\
\text { - Sinus CT demonstrating } \\
\text { - Bone erosion } \\
\text { - Sinus expansion } \\
\text { - Extension of disease into adjacent } \\
\text { anatomic areas }\end{array}$ \\
\hline $\begin{array}{l}\text { Other diagnostic } \\
\text { measures }\end{array}$ & $\begin{array}{l}\text { Possible, but not required: } \\
\text { - Fungal culture } \\
\text { - Total serum IgE } \\
\text { - Imaging by more than one technique }\end{array}$ \\
\hline
\end{tabular}

et al have described the $\mathrm{CT}$ and M RI findings in patients with AFRS. There is characteristic serpiginous attenuation in CT scan particularly in bone window. ${ }^{36}$ Ferromagnetic elements produced by fungi are believed to be the cause of this heterogeneous destruction. The combination of hyperattenuation and bony erosion on CT scan and type 1 hypersensitivity may be considered as preoperative predictors of $\mathrm{AFRS}^{36}$ (Fig. 1).

$\mathrm{MRI}$ is complimentary to CT scan and done in cases with intraorbital or intracranial extension of disease on CT scan. On M RI, there is a central low signal on $\mathrm{T} 1$ and $\mathrm{T} 2$ imaging by sinuses that correspond with areas of eosinophilic mucin (Fig. 2). Peripheral high-signal intensity

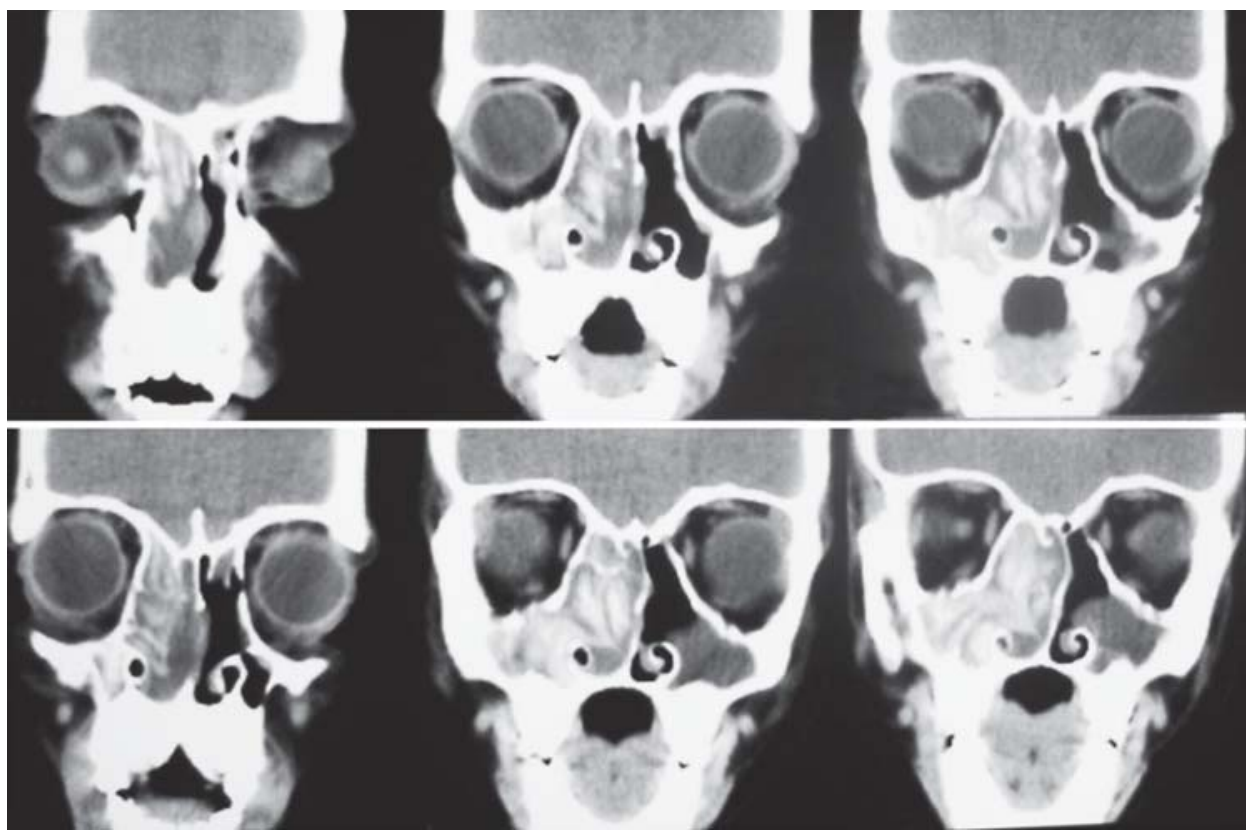

Fig. 1: CT scans showing characteristic hyperattenuation seen in AFRS 


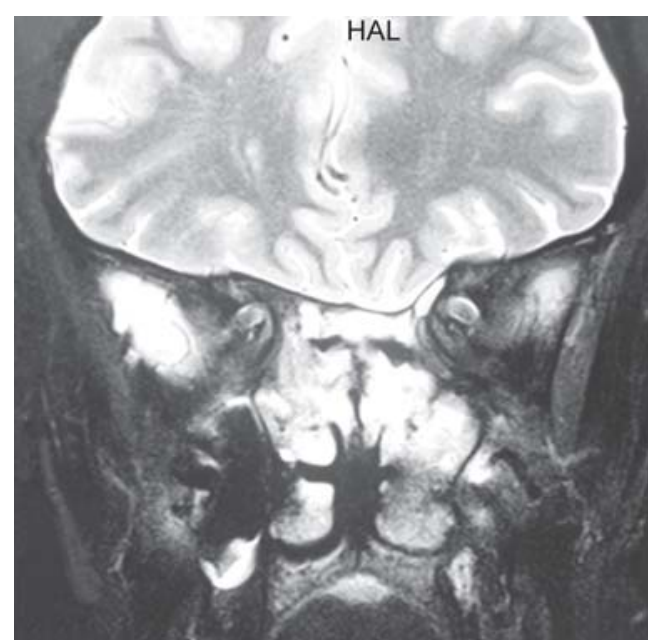

Fig. 2: T2 weighted MRI showing demonstrates hypointense regions surrounded by mucosal inflammation

corresponds with inflamed mucosa. ${ }^{37-39} \mathrm{M} \mathrm{RI}$ demonstrates hypointense regions surrounded by mucosal inflammation in T 2 weighted images. M anning et al in a series of 10 cases of AFRS, demonstrated that hypointense central T1 signal, central T2 signal void, and the presence of increased peripheral T1/T2 enhancement was highly specific for AFRS as compared with other forms of fungal sinusitis (invasive fungal sinusitis and fungal ball) and mucocele. ${ }^{38}$

CT findings of sinus expansion with central areas of irregular high attenuation should prompt suspicion for A FS. B ony erosion noted is likely due to pressure resorption but may be due to the effect of inflammatory mediators. Although the CT scan and MRI findings in AFRS are considered important in diagnosis, definitive diagnosis requires histologic verification and other clinical information (Figs 3 and 4).

\section{Treatment}

W ith the better understanding and recognition of the disease process, the treatment of AFRS has also evolved from aggressive radical surgery and toxic antifungal medications to conservative endoscopic surgery and adjunctive medical therapy directed at suppressing inflammation and reducing

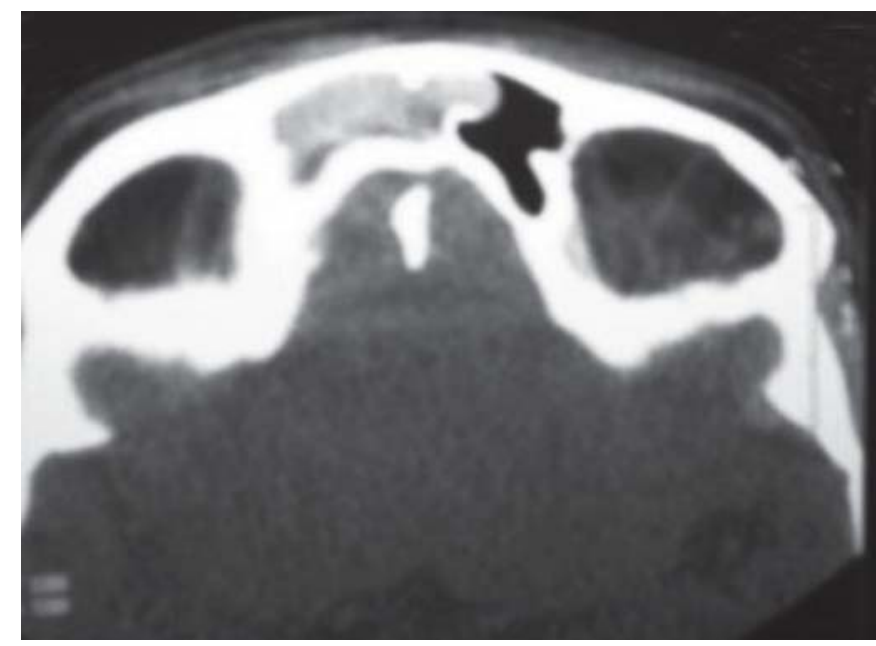

Fig. 4: CT scan showing hetrodense shadow in frontal sinus suggestive of AFRS

the burden of fungal antigen in the nose. The recognition of AFRS now, to be a noninvasive, immunologically mediated hypersensitivity to fungal antigens has lead to the treatment options to be considered accordingly.

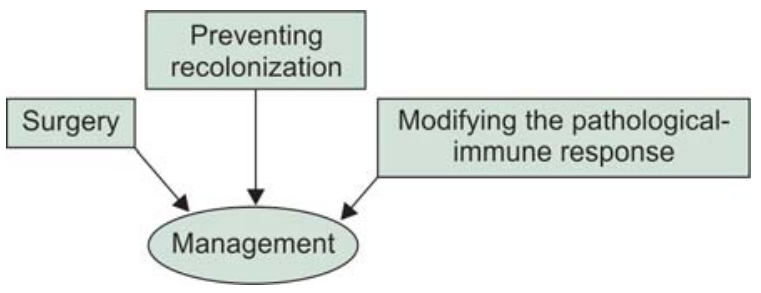

The treatment of AFRS is surgical extirpation of the allergic mucin and fungal muck and providing drainage and aeration of the sinuses. External radical approaches with removal of the sinus mucosa were done earlier ${ }^{40,41}$ but with the advent of nasal endoscopes, most cases are amenable to tissue preserving endoscopic approach. ${ }^{28}$ External surgeries are not necessary except in rare circumstances and obliterative procedures should be avoided. $\mathrm{N}$ asal polyposis is inherent to AFR S and can range from subtle to extensive, distortion of local anatomy and loss of useful surgical landmarks which increases the risks of complications during surgery. Image guidance can be an important tool for
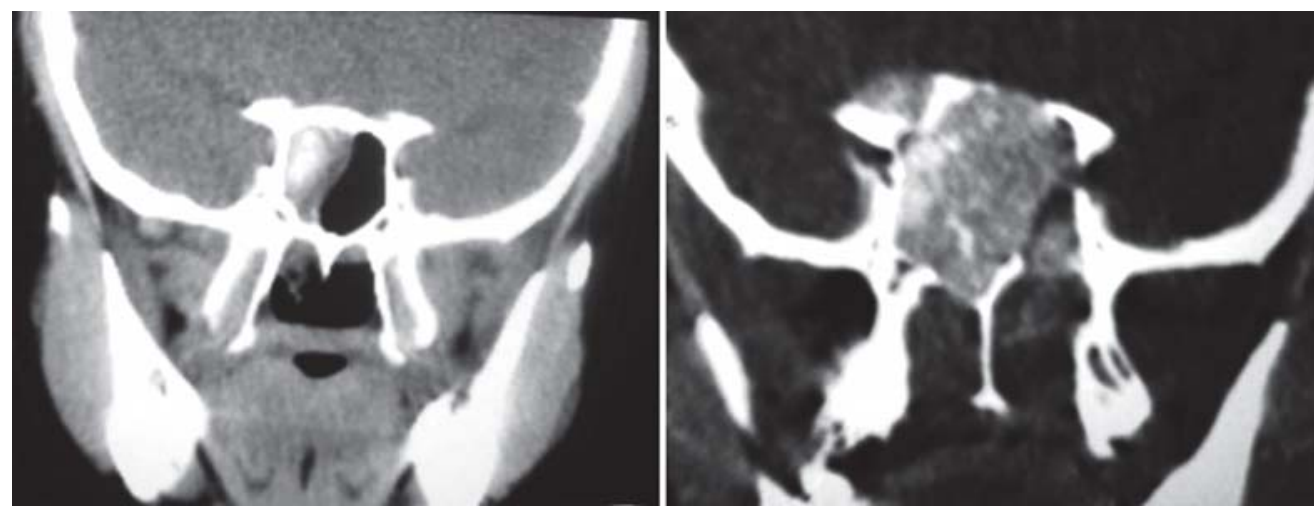

Fig. 3: CT scan showing hetrodense shadow in sphenoid sinuses suggestive of AFRS 
facilitating a complete surgery as missing diseased cells with eosinophilic mucin would decrease the effectiveness of medical treatment and increase the chances of recurrence. ${ }^{42}$

In cases of recurrence, if the medical management fails to clear an exacerbation, eosinophilic mucin accumulation and polyposis, then surgical treatment is warranted which would need a more aggressive surgery and wide sinusotomies. Regardless of the completeness of surgical exenteration, recurrences are common. Hence, the need for medical adjuncts following surgery is mandatory.

M edical treatment for A FRS is essential to obtain longterm symptom control, retard polyp formation and delay or prevent revision surgery. Different forms of medical therapies ranging from immunotherapy to systemic steroids have been used for treating AFRS though randomized blinded clinical trials are lacking. Systemic antiinflammatory agents are usually required in the treatment of AFRS and appear to be the most effective medical therapy. Systemic steroids are at least transiently effective for the treatment of polypoid rhinosinusitis as shown by a few placebo controlled, randomized trials $s^{43,44}$ so may be used as an adjunct after surgery. The side effect profile of systemic corticosteroids warrants careful consideration when they are used in a long-term approach to control A FRS. Therefore, as a general rule, systemic steroids are best confined to the perioperative period and for use in short bursts to suppress recurrent polyps and address acute exacerbations of disease. Topical intranasal steroids play an important role in the long-term medical management of AFRS. Topical delivery avoids or minimizes most of the acute and chronic long-term toxicities of corticosteroids, yet is successful in maintaining control of inflammation for prolonged periods. Topical steroids have been shown to be effective in the treatment of nasal polyp disease in AFRS ${ }^{45}$ and in higher doses than normal. ${ }^{46}$ Budesonide has been tried in the form of atomized spray as it would deliver a larger total dose of steroid compared with conventional steroid nasal sprays. ${ }^{47}$ Unfortunately, although topical intranasal steroids appear to be effective, they are often not sufficient to completely eliminate the use of systemic steroids.

The recognized toxicity of repeated courses of systemic steroids has led to a search for nonsteroid treatment al ternatives. $\mathrm{M}$ acrolides ${ }^{30}$ and leukotriene receptor antagonists or synthesis inhibitors have also been tried for polypoid CRS because of their safety and possible steroidsparing effect though it lacks effective control. ${ }^{48}$

Systemic antifungal therapy for AFRS was initially proposed to control the theoretical potential for progression to invasive forms of fungal sinusitis. The early use of amphotericin B yielded to the use of less toxic agents, such as ketoconazole, itraconazole and fluconazole, but the poor in vivo activity of these agents against dematiaceous fungi was soon discovered. ${ }^{11}$ The role of antifungals had been controversial and one view is that these are too expensive and toxic for routine use, but some studies however, reported good result with the use of systemic itraconazole therapy. ${ }^{49-51}$ None of these studies however, gave any evidence that antifungals decrease reliance on systemic steroids. M oreover, the efficacy of agents such as itraconazole may not be due to a reduced fungal burden in the nose, but rather due to the anti-inflammatory properties of the molecule or its inhibition of prednisone metabolism. Antifungal treatments are sometimes employed for A FRS with the aim of decreasing the fungal exposure within the sinonasal cavities. $^{46,52}$ Like systemic antifungals, there have been no trials of topical antifungals specifically for AFRS. Randomized, controlled trials have failed to show a significant therapeutic benefit of topical antifungal (amphotericin) for the treatment of chronic polypoid rhinosinusitis. ${ }^{53}$ Despite the purported fungal cause of AFRS, antifungal therapies need further investigation to establish their efficacy before their use is widely adopted.

I mmunotherapy is another treatment modality that holds potential as an effective treatment option for AFRS. The anti-inflammatory effect of specific allergen immunotherapy has the potential to decrease reliance on systemic steroids in the treatment of A FRS or may reduce the need for revision surgery. Although the relative importance of type 1 hypersensitivity in AFRS continues to be debated, the rationale for immunotherapy is that A FRS is at least partially a result of allergen-specific IgE-mediated inflammation. The evidence to support the use of immunotherapy was incidenta $\left.\right|^{54,55}$ In a nonrandomized not double blinded study on comparing AFRS patients treated with and without immunotherapy with an average 33 months of follow-up, Folker et al showed that the immunotherapy treated patients had better endoscopic mucosal appearance, lower CRS survey scores, required fewer courses of oral steroids ( 0 vs 2 ), and showed less reliance on nasal steroids ( 27 vs $73 \%)$. At present therapy for AFRS is directed toward reducing inflammation and reducing fungal antigen exposure. ${ }^{5}$ Significant uncertainty about the ideal treatment approach will persist as long as high-level evidence from randomized, controlled trials is lacking.

\section{Follow-up}

Follow-up of the patients can be done according to the following criteria:

a. Visual analog scale: Clinical symptoms like nasal obstruction, olfactory dysfunction, rhinorrhea, facial pain, sneezing, headache and visual symptoms are evaluated with a visual analog scale (VAS) ranging from 0 (no symptoms) to 10 (maximum symptoms). The severity of each symptoms collected from the results of 
the VAS can be graded into four categories according to the results of the VAS.

b. Endoscopic physical findings: Objective assessment by rigid nasal endoscopy following surgery can be done by a standard endoscopic staging system described by K upferberg et al:

- Stage 0: No evidence of disease

- Stage 1: M ucosal edema \pm allergic mucin

- Stage 2: Polypoid mucosa \pm allergic mucin

- Stage 3: Polyposis with allergic mucin

c. Objective CT score- can be done based on L und M ackay staging system that attributes points based on sinomucosal disease, opacification and obstruction:

- 0 point: No abnormality

- 1 point: Partial opacification

- 2 points: Total opacification

Points are calculated by adding for each sinus and on both sides.

\section{Interpretation of Lund and Mackay Staging System}

- 0 to 4: Normal

- 5 to 9: M inimal

- 10 to 14: Moderate

- 15 to 24: Severe

\section{Recurrence of Disease}

The potential for AFRS recidivism is well-recognized and ranges from 10 to $100 \%$ depending on the length of follow-up. To emphasize the importance of long-term surveillance, B ent et al pointed out that in their experience the often-dramatic initial response to surgical therapy was eventually replaced by recurrence of AFRS in the absence of ongoing therapy. ${ }^{27}$ Similarly K upferberg et al followed the appearance of sinonasal mucosa of 24 patients treated with combined medical and surgical therapy for AFRS. Nineteen of 24 eventually developed recurrence of disease after discontinuation of systemic steroids, but they observed that endoscopic evidence of disease generally preceded return of subjective symptoms. AFRS recidivism appears to be influenced by long-term postoperative therapy. ${ }^{56}$

Incian perspective Consensus arrived by a national panel on AFRS at the ENT Surgical U pdate 2011, held at P ostgraduate Institute of M edical Education and Research, Chandigarh.

\section{Preoperative Workup and Preparation}

Imaging: CT scan of nose, paranasal sinuses with orbits, axial, coronal and sagittal sections is manadatory in all patients to be taken up for surgery. Patients having intraorbital or intracranial extension of disease on CT scan to be subjected to a M RI. CT findings of sinus expansion with central areas of irregular high attenuation should prompt suspicion for AFS.

Workup for general anesthesia: All routine hematological and biochemical investigations necessary to obtain fitness for surgery to be done.

Preoperative steroids: Oral prednisolone in a dose of 0.5 $\mathrm{mg} / \mathrm{kg}$ body weight to be started 2 weeks preoperatively. Oral deflazacort to be preferred in diabetic patients in a dose of $0.5 \mathrm{mg} / \mathrm{kg}$.

\section{Surgical Management}

Consensus was reached that endoscopic sinus surgery to be preferred, reserving the open approach for rare circumstances. The role of surgery in patients of AFRS is to remove all the obstructing inspissated allergic mucin and to address the diseased mucosa establishing a permanent aeration of the sinuses. Early surgery warranted in all cases especially in all patients especially having intraorbital or intracranial extension of disease.

\section{Postoperative Management}

The experts were of the opinion that oral prednisolone or deflazacort in a dose of $0.5 \mathrm{mg} / \mathrm{kg}$ body weight should be used for 3 to 6 months. Topical steroidal sprays to be continued for 6 months and then as and when required. In the topical steroids, fluticasone furoate has a better compliance than mometasone or budesonide. The role of systemic antifungals in patients with intracranial and intraorbital extension of disease was debated. These are being used but because of lack of scientific evidence, all the panelists were of the opinion that further studies are required before any conclusion can be drawn. This protocol would be reviewed again after one year. Saline douches to be continued preferably lifelong. Further, it was deliberated that leukotriene receptor antagonists are not effective. Thirty percent of the experts were of the opinion that these are not effective and $30 \%$ said they are effective while the rest $40 \%$ had not used them. Role of immunotherapy in India has yet not been established.

\section{Follow-up}

Postoperative endoscopic suction and clearance to be done weekly for 1 month bimonthly for 3 months, once a month for 6 months and then 3 monthly for 5 to 6 years. It was further proposed to get postoperative CT scan after 6 weeks and then as and when required.

\section{Recurrent Disease}

The first line of treatment for recurrence is medical therapy in the form of oral and topical steroids. If the patient fails 
medical therapy, revision endoscopic surgery to be done after adequate imaging. Patient to be labeled as diseasefree, if there is no radiological evidence of disease on CT scan for 5 years.

\section{DISCUSSION}

Fungus is ubiquitous, present in all our surroundings and the air we inhale. M ost healthy people do not react to the presence of fungus due to a functioning immune system. However, in rare instances, fungus may cause inflammation in the nose and the sinuses. Fungal sinusitis can manifest in various forms, differing in pathology, symptoms, course, severity and the treatment required.

A simplified classification of fungal sinusitis is as follows:

A. Noninvasive fungal sinusitis

i. Fungus ball

ii. Allergic fungal sinusitis

iii. Nonallergic fungal sinusitis

B. Invasive fungal sinusitis

i. A cute invasive fungal sinusitis

ii. Chronic invasive fungal sinusitis

iii. Granulomatous invasive fungal sinusitis.

We would be restricting ourselves to AFRS. AFRS is a distinct form of chronic polypoid rhinosinusitis characterized by accumulation of eosinophilic mucin with fungal hyphae in the sinuses, type 1 hypersensitivity to fungi, and a propensity for mucocele formation and bone erosion (Figs 5 and 6).

As mentioned earlier, approximately 5 to $10 \%$ of those patients with chronic rhinosinusitis carry a diagnosis of AFRS. ${ }^{2}$ It is most common among adolescents and young adults (mean age, 21.9 year). ${ }^{11}$ The incidence of AFRS appears to be impacted by geographic factors. In India, A FRS is reported from North and South India because of hot and humid conditions. ${ }^{17-19}$

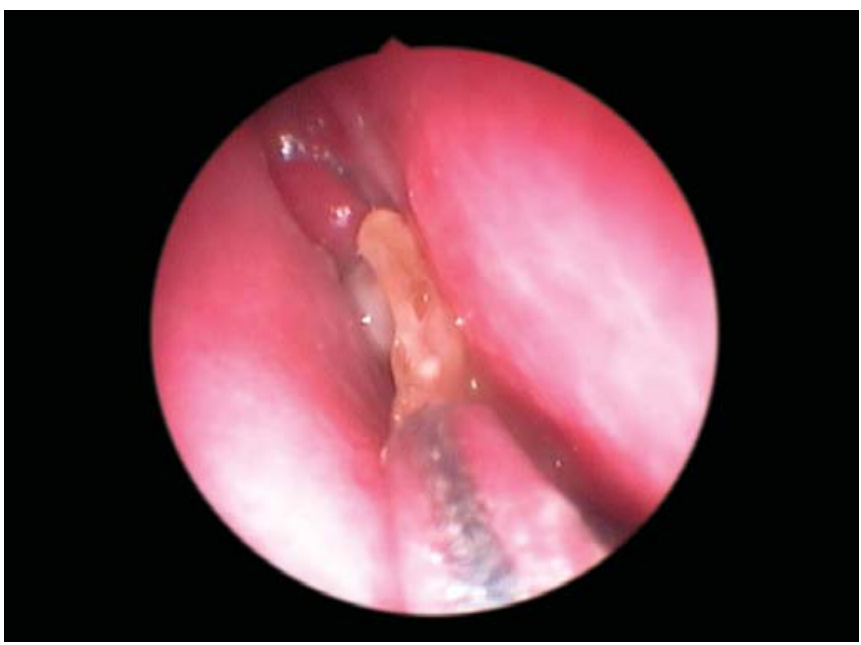

Fig. 5: Endoscopic picture showing thick, tenacious allergic mucin

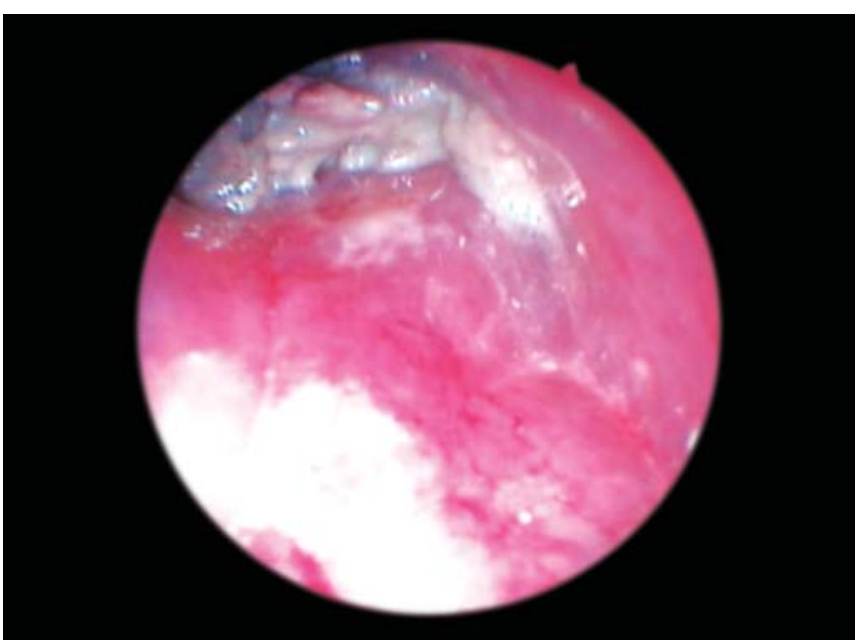

Fig. 6: Endoscopic picture showing fungal muck

Patients with AFRS usually present with rhinosinusitis symptoms lasting months or years and they may not seek medical attention until complete nasal obstruction, headaches, visual disturbances or facial distortion develop. Proptosis or telecanthus are frequently seen at presentation, especially in younger patients. ${ }^{17,28,57,58}$ (Figs 7 to 9 ).

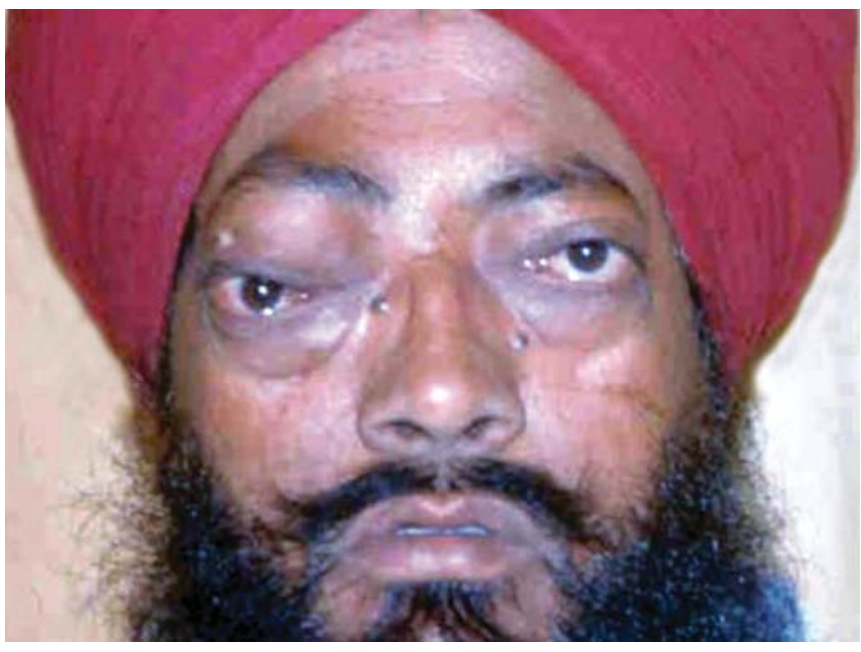

Fig. 7: Clinical photograph showing proptosis of eye

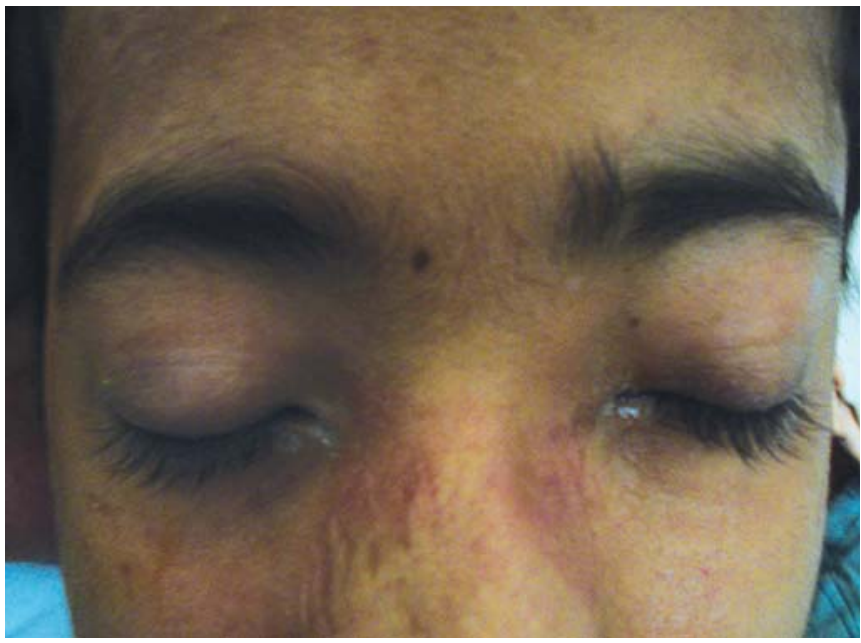

Fig. 8: Clinical photograph showing telecanthus 


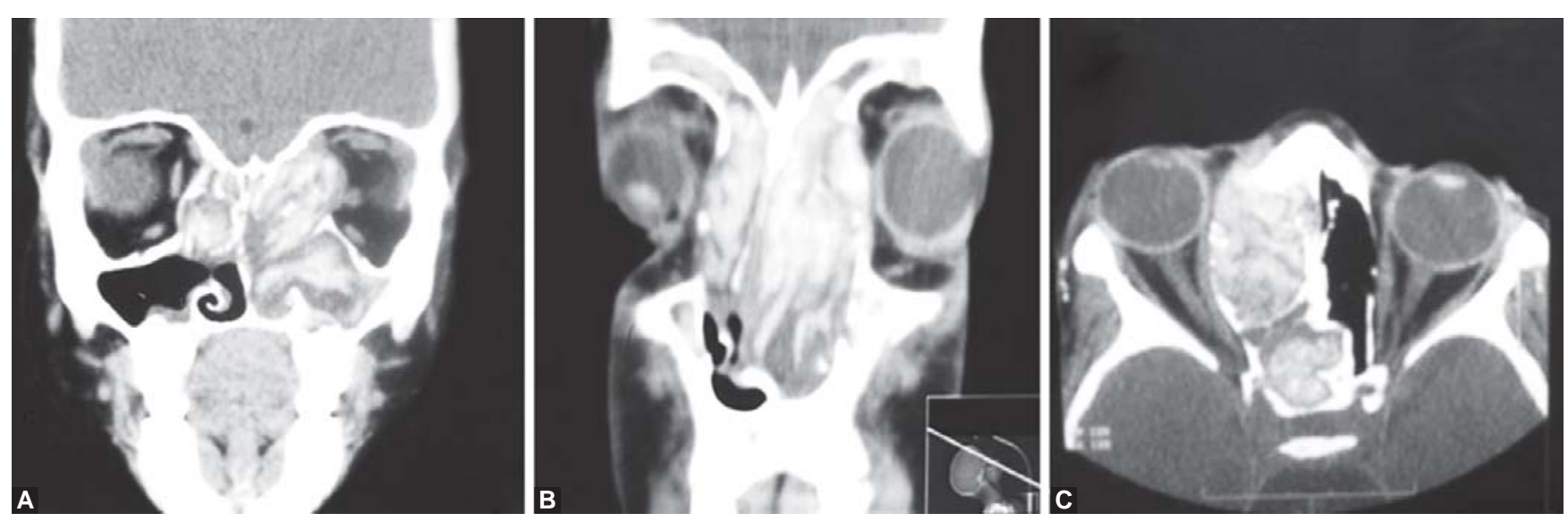

Figs 9A to C: (A and B) Coronal sections CT scan showing intraorbital extension, (C) axial section CT scan showing intraorbital extension

Gupta et al in a study compared A FRS in adults and children and found that clinical profile of both the groups was the same except for higher incidence of proptosis in pediatric cases ( $60 \%$ as compared to $20 \%$ in adults) and high chances of having coexistent asthma and rhinobronchial allergy in adults ( $50 \%$ compared to $1 \%$ in children). There was higher incidence of facial deformities in the children compared to adults in their study with proptosis in $60 \%$, telecanthus in $40 \%$ and nasal pyramid widening in $18 \%$ children and 20 , 9 and $0 \%$ in adults respectively. ${ }^{17} \mathrm{M} \mathrm{cClay}$ has reported an incidence of $42 \%$ facial deformities in children compared to $10 \%$ in adults. ${ }^{57} \mathrm{G}$ upta et al found a higher incidence of facial deformities, proptosis, intraorbital/intracranial extension and a higher rate of recurrence in children, with an earlier presentation, therefore, suggesting a more aggressive nature of AFS in children than adults mandating an early diagnosis, proper management and regular follow-up in these cases. ${ }^{17}$ On radiology the involvement of the sinuses has been found to be asymmetrical in $70 \%$ of the children compared to $30 \%$ in adults ${ }^{17}$ and similar findings have been found by other authors. ${ }^{16,57}$ The involvement of orbit was seen more commonly with the children (68\%) compared to adults (33\%) Similarly, the intracranial extension was seen more often in children than adults. ${ }^{17}$ It is in accordance with the findings by $\mathrm{M} \mathrm{cClay}$ et al. ${ }^{57}$ Overall bony erosion was seen in $88 \%$ of the children compared to $36 \%$ in adults. $V$ arious studies quote a range of 20 to $90 \%$ incidence of bone erosion..$^{59} \mathrm{M}$ cClay reported an incidence of $25 \%$ bone erosion in children compared with $23 \%$ in adults. ${ }^{57}$

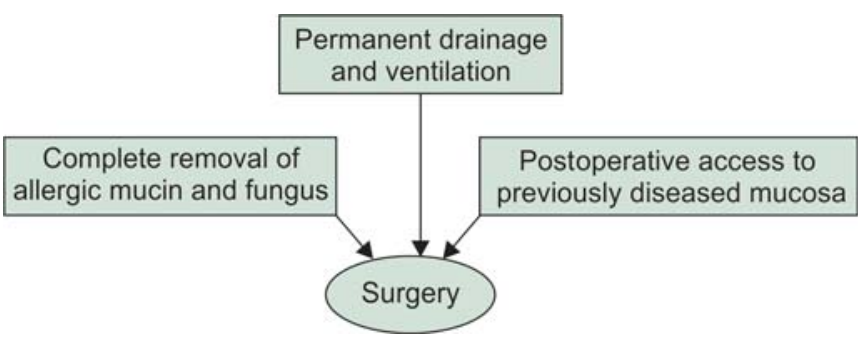

The treatment of AFRS is surgical extirpation of the allergic mucin and fungal muck and providing drainage and aeration of the sinuses with endoscopic sinus surgery being preferred overexternal approaches (Figs 10 and 11).

Preoperative steroids have been proved beneficial in obtaining a better operative field as well as having a better disease control. ${ }^{28,30}$
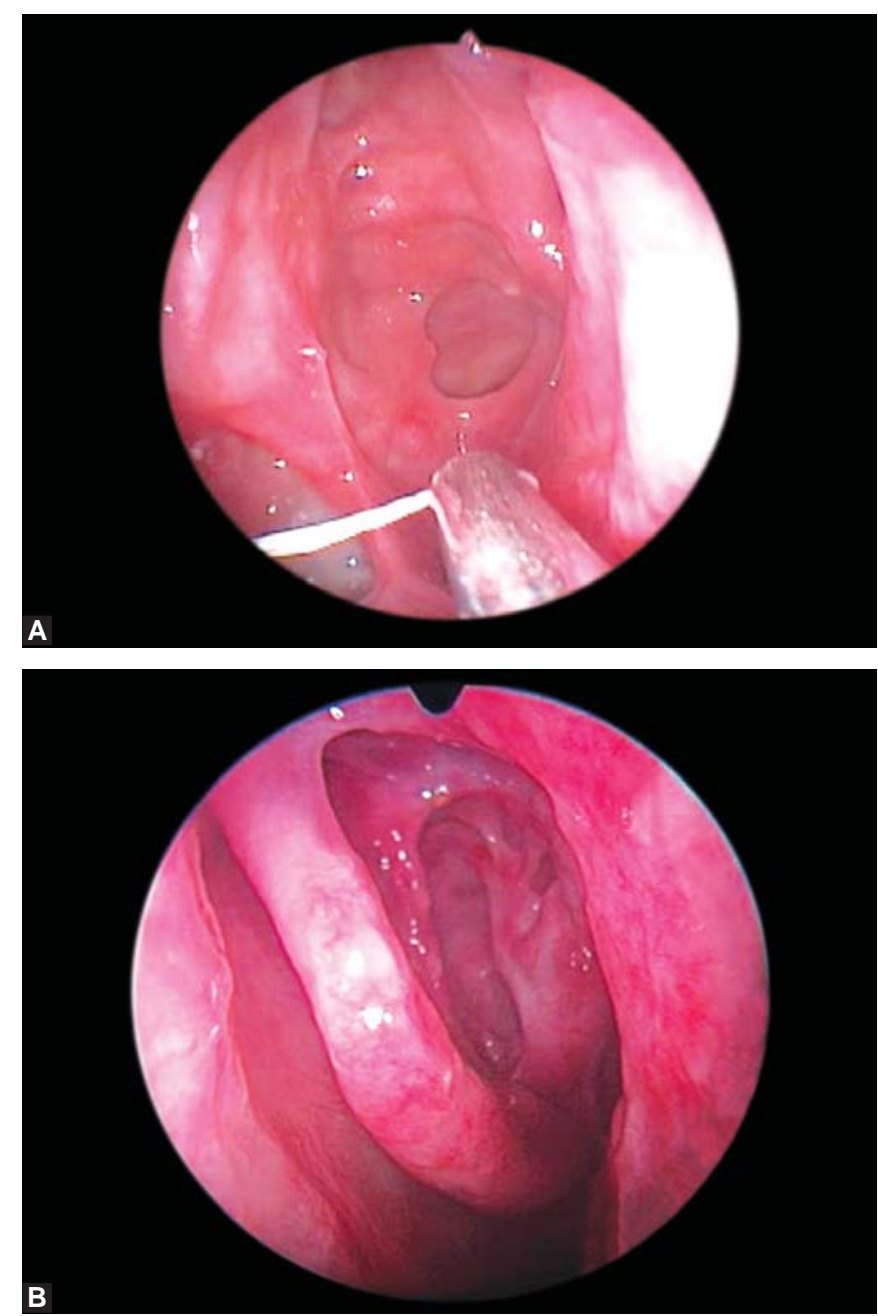

Figs 10A and B: Endoscopic pictures show well-healed postoperative cavities 


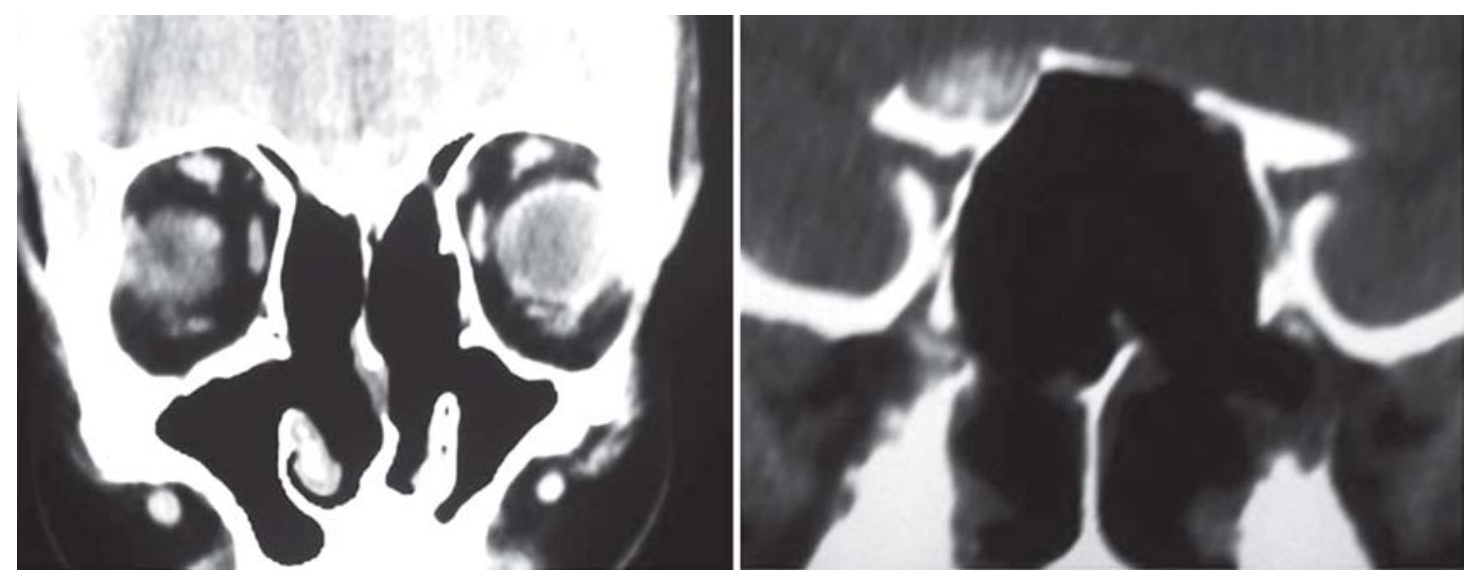

Fig. 11: CT scan showing postoperative maxillary and sphenoid sinuses

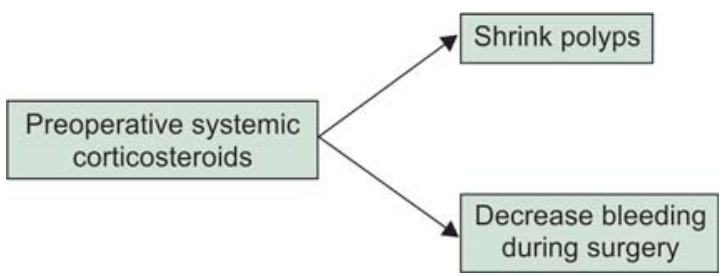

K ennedy et al conducted a prospective study to evaluate the effect of preoperative high dose systemic corticosteorids and radiographic and endoscopic appearance of AFRS. ${ }^{60}$ They reported a marked reduction of Lund-M ackay scores following high dose steroids. ${ }^{61}$ They advocated minimally invasive endoscopic sinus surgery following therapy with steroids. Furthermore, a short course of preoperative systemic corticosteroids will shrink polyps and decrease bleeding during surgery ${ }^{28} \mathrm{~K}$ insella et al who reviewed a series of 15 patients who underwent variable postoperative medical therapy for A FRS found that of the seven patients who had no recurrence at 6 months follow-up, four had been administered oral steroid for 2 to 4 weeks postoperatively. None of the eight patients with recurrent disease had received oral steroid. ${ }^{62}$ Similar encouraging results were found by DeShazo and Swain. ${ }^{63}$ B oth groups of researchers while recommending the use of oral steroids in the postoperative period based on anecdotal evidence highlighted the need for prospective, controlled studies. Schubert and Goetz ${ }^{30}$ further studied the role of systemic corticosteroids in the postoperative management AFRS, demonstrating a significant increase in the time to revision sinus surgery in those patients with AFRS who received prolonged courses of postoperative corticosteroids. Postoperative corticosteroid therapy in this study ranged from 2 to 12 months, with improved outcomes recorded among those patients who were placed on longer courses of therapy. K upferberg et al in a review of 28 patients with AFRS stressed the role of systemic corticosteroids after endoscopic sinus surgery. Patients who received corticosteroids postoperatively had less recurrence compared to the patients who did not receive steroids. They recommended oral prednisolone at a dose of $40 \mathrm{mg} /$ day for 4 days, $30 \mathrm{mg} /$ day for 4 days and $20 \mathrm{mg} /$ day for 1 month. The dose was then adjusted to the lowest possible dose at which the patient could be maintained at stage $0 .{ }^{56} \mathrm{~K}$ uhn and J aver followed a protocol lasting about 7 months with prednisolone being administered in a tapering dose starting at $40 \mathrm{mg} / \mathrm{day}$ and maintained at $0.1 \mathrm{mg} / \mathrm{kg}$ day for the last 2 months of treatment. ${ }^{46}$ The long duration of therapy was essentially to maintain a recurrence free state. The use of concomitant high-dose inhaled steroid was al so emphasized. However, long-term treatment with systemic corticosteroids increases the risk of both acute and long-term morbidity particularly in children. The effect of corticosteroids in growth and bone development are extremely important in the pediatric population. Studies have shown that long-term systemic steroid usage can cause developmental growth delay and bone demineralization. In a study by Chesney et al children with childhood glomerular disease receiving prednisone were $5.3 \%$ shorter and had $16.7 \%$ more demineralization than matched control subjects. ${ }^{64}$ Shegren et al experimentally proved that alternate day dosing lessened the effect of corticosteroids but still cause premature closure of epiphyseal plates. Linear growth may be inhibited by a little as $5 \mathrm{mg}$ of prednisone per day or 30 mg every other day. ${ }^{65}$ Schubert et al reported no adverse effects among their series of 67 patients with A FRS treated for up to 1 year with systemic corticosteroids, but longterm follow-up for this form of therapy is lacking. ${ }^{30}$ In view of these side effects, the panel recommended steroids in the form of prednisolone to be started 2 weeks preoperatively and 3 to 6 months postoperatively in a dose of $0.5 \mathrm{mg} / \mathrm{kg}$ body weight rather than $1 \mathrm{mg} / \mathrm{kg}$ body weight. ${ }^{66}$

Topical intranasal steroids play an important role in the long-term medical management of A FRS. Topical delivery avoids or minimizes most of the acute and chronic 
long-term toxicities of corticosteroids, yet is successful in maintaining control of inflammation for prolonged periods.

$M$ acrolides $^{30}$ and leukotriene receptor antagonists or synthesis inhibitors have also been tried for polypoid CRS because of their safety and possible steroid-sparing effect though it lacks effective control. ${ }^{48}$

Systemic antifungal therapy for AFRS was initially proposed to control the theoretical potential for progression to invasive forms of fungal sinusitis. The early use of amphotericin B yielded to the use of less toxic agents, such as ketoconazole, itraconazole and fluconazole, but the poor in vivo activity of these agents against dematiaceous fungi was soon discovered. ${ }^{11}$ Systemic antifungals are too expensive and toxic for routine use, but some studies however, reported good result with the use of systemic itraconazole therapy ${ }^{49-51,67}$ probably because of their antiinflammatory properties. Randomized, controlled trials have failed to show a significant therapeutic benefit of topical antifungal (amphotericin) for the treatment of chronic polypoid rhinosinusitis. ${ }^{53}$

In accordance with the literature, the panel concluded that leukotriene receptor antagonists are not effective and antifungal irrigation has no role while systemic antifungals have any role except in repeated recurrences. The advantages and usefulness of saline douches was emphatically stressed by the panel and preferably to be continued lifelong.

Immunotherapy may be a effective treatment option for AFRS as it is at least partially a result of allergen-specific IgE-mediated inflammation. Although subcutaneous immunotherapy has clearly demonstrated efficacy in allergic rhinitis and asthma ${ }^{68,69}$ randomized, controlled trials that examine the efficacy of immunotherapy specifically for AFRS are lacking. There are chances of worsening of disease due to introduction of foreign extraneous fungal antigens and damage to tissues due to type III Gel and Coomb's occasionally. Moreover, there is lack of availability of pure extracts to specific fungal antigens in India. In view of lack of substantial high-level evidence from randomized, controlled trials, a consensus was reached at the meeting that immunotherapy in the current form has no role in AFRS.

In cases of recurrence, if the medical management fails to clear an exacerbation, eosinophilic mucin accumulation and polyposis, then surgical treatment is warranted which would need a more aggressive surgery and wide sinusotomies (Figs $12 \mathrm{~A}$ and $\mathrm{B}$ ).

The panel categorically emphasized the importance of long-term surveillance in cases of AFRS and a follow-up schedule by nasal endoscopic examination and CT scan was suggested to look for recurrence and recidivism. AFRS recidivism appears to be influenced by long-term
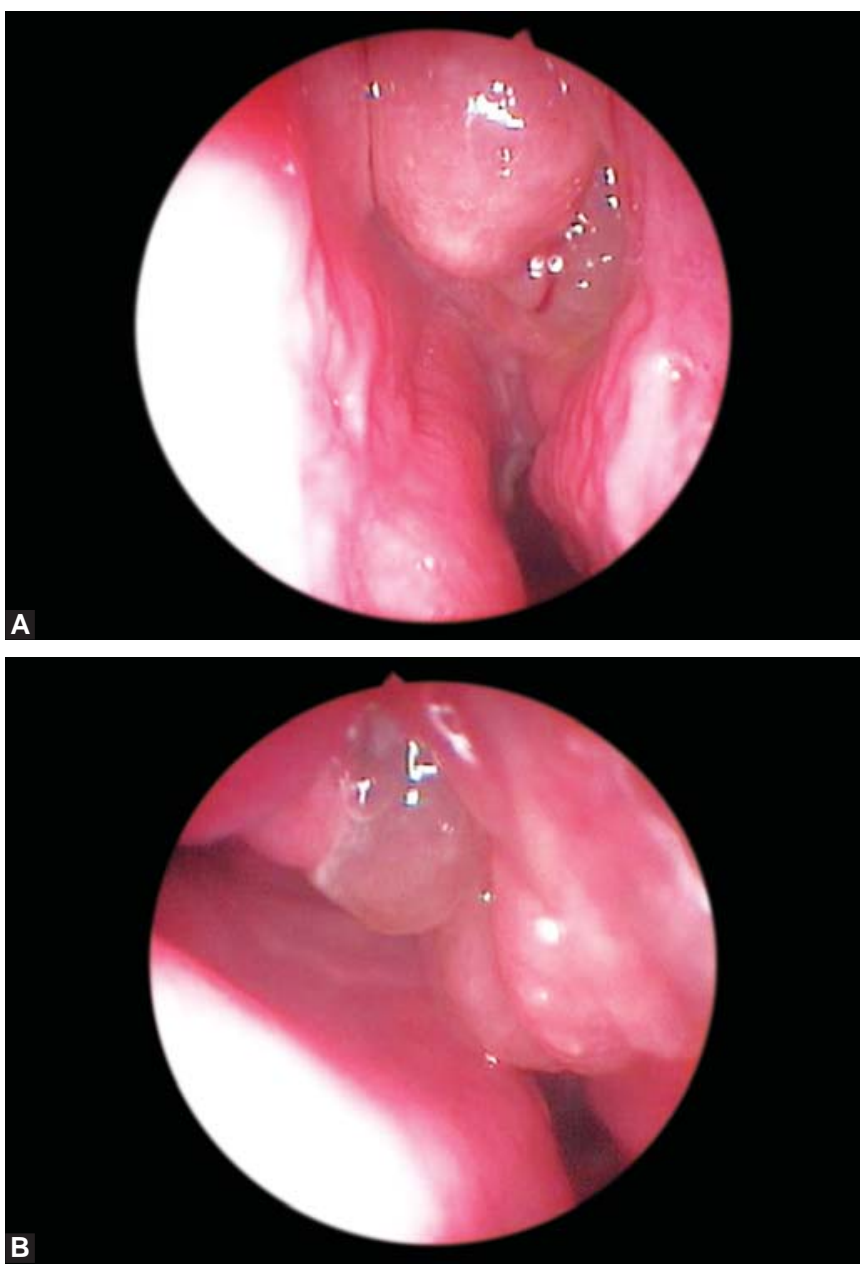

Figs 12A and B: Endoscopic pictures showing recurrence of the disease

postoperative therapy. Schubert et al reported the long-term clinical outcome of 67 patients following initial surgical therapy for A FRS. Patients treated with at least 2 months of oral corticosteroids were compared with those who received no corticosteroids. At 1 year after initial surgery, patients treated with oral corticosteroid were significantly less likely to have experienced recurrent AFRS. ${ }^{30}$ It is important to realize that AFRS recidivism remains high despite appropriate postoperative medical therapy. Nasal endoscopy at regular intervals is the best way to monitor the activity of disease, and patients should be encouraged to return early for any symptom exacerbation.

\section{KEY POINTS}

Indian perspective: Consensus arrived by a national panel on AFRS at the ENT surgical update 2011, held at PGI, Chandigarh.

1. CT scan of nose and PNS with axial, coronal and sagittal sections manadatory for endoscopic sinus surgery.

2. Role of preoperative steroids: Oral prednisolone to be started in normal patients and deflazacort in diabetics in a dose of $0.5 \mathrm{mg} / \mathrm{kg}$ body weight preoperatively. 
3. Early surgery warranted in all cases especially in patients having intraorbital or intracranial extension of disease.

4. Endoscopic approach to be preferred for surgery.

5. The role of surgery in patients of AFRS is to remove all the obstructing inspissated allergic mucin and to address the diseased mucosa establishing a permanent aeration of the sinuses.

6. Postoperative steroids: O ral prednisolone or deflazacort in a dose of $0.5 \mathrm{mg} / \mathrm{kg}$ body weight for 3 to 6 months. Topical steroidal sprays to be continued for 6 months and then as and when required.

7. Fluticasone furoate has a better compliance than mometasone or budesonide.

8. No antifungal irrigation or any systemic antifungals have any role except in repeated recurrences.

9. Saline douches to be continued preferably lifelong.

10. Leukotriene receptor antagonists are not effective.

11. No role of immunotherapy in India yet.

12. Follow-up: Postoperative endoscopic suction and clearance weekly for 1 month bimonthly for 3 months, once a month for 6 months and then 3 monthly for 5 to 6 years. Postoperative CT scan after 6 weeks and then as and when required.

13. Recurrent disease: $M$ edical therapy in the form of oral and topical steroids to be tried first and if medical therapy fails, to be considered for endoscopic surgery.

14. Patient to be labeled as disease-free, if there is no radiological evidence of disease on $\mathrm{CT}$ scan for 5 years.

\section{REFERENCES}

1. Safirstein B. Allergic bronchopulmonary aspergillosis with obstruction of the upper respiratory tract. Chest 1976;70:788-90.

2. Katzenstein $A L$, Sal eSR, Greenberger PA . A llergic Aspergillus sinusitis: A newly recognized form of sinusitis. J Allergy Clin Immunol 1983;72:89-93.

3. Miller JW, Johnston A, L amb D. A llergic aspergillosis of the maxillary sinus [abstract]. Thorax 1981;36:710.

4. Erwin GE, Fitzgerald JE. Case report: Allergic bronchopulmonary aspergillosis and allergic fungal sinusitis successfully treated with voriconazole. J A sthma 2007;44:891-95.

5. Folker RJ , M arpleBF, M abry RL, etal. T reatment of allergic fungal sinusitis: A comparison trial of postoperative immunotherapy with specific fungal antigens. Laryngoscope 1998;108:1623-37.

6. Allphin AL, Strauss M , A ddul-K arin FW, et al. A llergic fungal sinusitis: Problems in diagnosis and treatment. Laryngoscope 1991;101:815-20.

7. Cody DT, N eel HB, Ferreiro J A, et al. Allergic fungal sinusitis: The mayo clinic experience. Laryngoscope 1994;104:1074-79.

8. Ferguson BJ. Eosinophilic mucin rhinosinusitis: A distinct clinicopathologic entity. Laryngoscope 2000;110:799-813.

9. Pant $H, K$ ette FE, Smith W B , et al. Eosinophilic mucus chronic rhinosinusitis: Clinical subgroups or a homogeneous pathogenic entity? Laryngoscope 2006;116:1241-47.
10. Ponikau JU, Sherris DA, Kern EB, Homburger HA, Frigas $E$, Gaffey TA, Roberts GD. The diagnosis and incidence of allergic fungal sinusitis. M ayo Clin Proc 1999;74(9):877-84.

11. M anning SC, Holman M. Further evidence for allergic pathophysiology in AFRS. Laryngoscope 1998;108:1485-96.

12. Stewart $A E$, Hunsaker DH. Fungus-specific IgG and IgE in allergic fungal rhinosinusitis. Otolaryngol Head Neck Surg 2002; 127:324-32.

13. F eger $T$, R upp N, K uhn F, et al. L ocal and systemic eosinophil activation. A nn A llergy A sthma I mmunol 1997;79:221-25.

14. L uong A, Davis LS, M arple BF. Peripheral blood mononuclear cells from allergic fungal rhinosinusitis adults express a Th2 cytokine response to fungal antigens. A m J Rhinol Allergy 2009;23:281-87.

15. Ferguson $B J, B$ arnes $L, B$ ernstein J M , B rown D, Clark CE 3rd, Cook PR, et al. Geographical variation in A FRS. Otolaryngol Clin North A m 2000;33:441-49.

16. Gupta AK, Ghosh S. Sinonasal aspergillosis in immunocompetent Indian children: An eight year experience, M ycoses 2003;46: 455-61.

17. Gupta AK, Bansal S, Gupta A, M athur N. Is fungal sinusitis more aggressive in children than adults? - A study of 200 cases. Int J Pediatr Otorhinolaryngol 2006;70(4):603-08.

18. D hiwakar M, Thakar A, B ahadur S, Sarkar C, B anerji U, H anda $\mathrm{KK}$, et al. Prospective diagnosis of allergic fungal sinusitis. Laryngoscope 2003;113:688-94.

19. Rupa V, Jacob M, M athews M S, Seshadri MS. A prospective, randomised, placebo-controlled trial of postoperative oral steroid in AFRS. Eur A rch Otorhinolaryngol 2009;10:1075-78.

20. Ence BK, Gourley DS, Jorgensen NL, et al. A llergic fungal sinusitis. Am J Rhinol 1990;4(5):169-78.

21. M anning SC, Schaefer SD, Close LG, et al. Culture-positive allergic fungal sinusitis. Arch Otolaryngol Head Neck Surg 1991;117:174-78.

22. Singh NN, Bhalodiya NH. Allergic fungal sinusitis-earlier diagnosis and management. J Laryngol Otol 2005;119:875-81.

23. M arple BF. Allergic fungal sinusitis. Curr Opin Otolaryngol 1999;7:383-87.

24. M arple BF, Gibbs SR, N ewcomer MT, M abry RL. A llergic fungal sinusitis-induced visual loss. A m J Rhinol 1999;13:191-95.

25. Gupta A K, B ansal S, Gupta A, M athur N. V isual loss in the setting of allergic fungal sinusitis: Pathophysiology and outcome. J L aryngo and Otol 2007;121(11):1055-59.

26. Loury M C, Schaefer SD. Allergic Aspergillus sinusitis. A rch Otolaryngol Head Neck Surg 1993;119:1042-43.

27. B ent JP 3rd, Kuhn FA. Diagnosis of allergic fungal sinusitis. Otolaryngol Head Neck Surg. 1994;111(5):580-88.

28. M arple BF. A llergic fungal rhinosinusitis: Current theories and management strategies. L aryngoscope 2001;111(6):1006-19.

29. M anning S, M abry R, Schaefer S, et al. Evidence of IgEmediated hypersensitivity in allergic fungal sinusitis. L aryngoscope 1993;103:717-21.

30. Schubert MS, Goetz DW. Evaluation and treatment of allergic fungal sinusitis. II: Treatment and follow-up. J Allergy Clin Immunol 1998;102:395-402.

31. M abry RL, M arple B F, Folker RJ, M abry CS. Immunotherapy for allergic fungal sinusitis: Three years' experience. Otolaryngol Head N eck Surg 1998;119:648-51.

32. M abry R, M anning S. R adioal lergosorbent microscreen and total immunoglobulin $\mathrm{E}$ in allergic fungal sinusitis. Otolaryngol Head Neck Surg 1995;113:721-23. 
33. M orpeth J F, Rupp NT, Dolen W K, B ent JP, K uhn FA. Fungal sinusitis: An update. Ann Allergy A sthma Immunol 1996;76: 128-40.

34. M eltzer EO, Hamilos DL, Hadley J A, et al. Rhinosinusitis: Establishing definitions for clinical research and patient care. JACI 2004;114:S155-212.

35. Ghegan M D, Lee FS, Schlosser RJ I Incidence of skull base and orbital erosion in allergic fungal rhinosinusitis (AFRS) and nonAFRS. Otolaryngol Head N eck Surg 2006;134:592-95.

36. Zinreich SJ, Kennedy DW, Malat J, et al. Fungal sinusitis; Diagnosis with CT and MR imaging. Radiology 1988;169: 439-44.

37. A ribandi $M, M$ cC oy $\vee A, B$ azan C. I maging features of invasive and noninvasive fungal sinusitis: A review. Radiographics 2007;27:1283-96.

38. $M$ anning $S C, M$ erkel $M, K$ riesel $K$, et al. Computed tomography and magnetic resonance diagnosis of allergic fungal sinusitis. L aryngoscope 1997;107:170-76.

39. Zinreich SJ, K ennedy DW, M alat J, et al. Fungal sinusitis: Diagnosis with CT and MR imaging. Radiology 1988;169: 439-44.

40. Killingsworth SM, W etmore SJ . Curvularia/D rechslera sinusitis. L aryngoscope 1990;100:932-37.

41. Zieske LA, K opkeRD, Hamill R. Dematiaceous fungal sinusitis. Otolaryngol Head Neck Surg 1991;105:567-77.

42. M arple BF, M abry RL. A llergic fungal sinusitis: L earning from our failures. Am J R hinol 2000;14:223-26.

43. Hissaria P, Smith W, Wormald PJ, et al. A short course of systemic steroids in sinonasal polyposis: A double-blind, randomized, placebo controlled trial with evaluation of outcome measures. J Allergy Clin Immunol 2006;118:128-33.

44. V an Zele T, Gevaert P, Holtappels $G$, et al. Oral steroids and doxycycline: Two different approaches to treat nasal polyps. J Allergy Clin Immunol 2010;125:1069-76.

45. Joe $S$, Thambi R, Huang J. A systematic review of the use of intranasal steroids in the treatment of chronic rhinosinusitis. Otolaryngol Head Neck Surg 2008;139:340-47.

46. Kuhn FA, Javer AR. Allergic fungal sinusitis: A four-year follow-up. Am J Rhinol 2000;14:149-56.

47. Kanowitz SJ, Batra PS, Citardi MJ. Topical budesonide via mucosal atomization device in refractory postoperative chronic rhinosinusitis. Otolaryngol Head Neck Surg 2008;139:131-36.

48. Schubert MS. A ntileukotriene therapy for allergic fungal sinusitis. J Allergy Clin Immunol 2001;108(3):466-70.

49. Swift, Denning. Skull base osteitis following fungal sinusitis. J Laryngol Otol 1998;112:92-97.

50. Denning DW, V an W ye JE, L ewiston N J. A djunctive treatment of allergic bronchopulmonary aspergillosis with itraconazole. Chest 1991;100:813-19.

51. Heykants J, Van de V elde V, V an Rooy P. The clinical pharmacokinetics of itraconazole: A n overview. M ycoses 1989; 32:67-87.

52. Erwin GE, Fitzgerald JE. C ase report: A llergic bronchopulmonary aspergillosis and allergic fungal sinusitis successfully treated with voriconazole. J A sthma 2007;44:891-95.

53. Weschta $M$, Rimek $D$, Formanek $M$, et al. Topical antifungal treatment of CRFS with nasal polyps: A randomized, double blind clinical trial. J Allergy Clin Immunol 2004;113:1122-28.

54. Goldstein MF, Dunksy EH, Dvorin DJ, et al. A llergic fungal sinusitis: A review with four illustrated cases. A m J Rhinol 1994;8:13-18.
55. Quinn J, Wickern G, Whisman B, et al. Immunotherapy in allergic Bipolaris sinusitis: A case report. J A llergy Clin Immunol 1995;95:201

56. K upferberg SB, B ent JP, K uhn FA. The prognosis of AFRS. Otolaryngol Head Neck Surg 1997;117:35-41.

57. M cClay JE, M arple B, K apadia L, et al. Clinical presentation of allergic fungal sinusitis in children. L aryngoscope 2002;112(3): 565-69.

58. Manning SC, Vuitch $F$, Weinberg A G, et al. Allergic aspergillosis: $A$ newly recognized form of sinusitis in the pediatric population. Laryngoscope 1989;99:681-85.

59. N ussenbaum B, Marple BF, Schwade ND. Characteristics of bone erosion in allergic fungal sinusitis, Otolaryngol. Head N eck Surg 2001;124:150-54.

60. K ennedy DW, W righted G ol dberg A N . O bjective and subjective outcomes in surgery for chronic sinusitis. Laryngoscope 2000; 110:29-31.

61. Lund VJ, Mackay IS. Staging in rhinosinusitis. Rhinology 1993;107:183-84.

62. Kinsella A, Bradfield JJ, Gourley WK, et al. AFRS. Clin Otolaryngol 1996; 21:389-92.

63. DeShazo RD, Swain RE. Diagnostic criteria for AFRS. J Allergy Clin Immunol 1995;96:24-35.

64. Chesney RW, Mazess RB, Rose P, et al. Effect of prednisone on growth and bone mineral content in childhood glomerular disease. AJOC 1978:132;768-72.

65. Sheagren JN, J owsey J, Bird DC, et al. Effects on bone growth of daily versus alternate-day corticosteroid administration - an experimental study. J Lab Clin M ed 1977;89:120-30.

66. I kram M, A bbas A, Suhail A, Onali M A, A khtar S, Iqbal M. $M$ anagement of allergic fungal sinusitis with postoperative oral and nasal steroids: A controlled study. Ear N ose Throat J 2009 A pril;88(4):E08.

67. Rains $B M, M$ ineck $C W$. Treatment of allergic fungal sinusitis with high dose itraconazole. A m J R hinol 2003;17(1):1-8.

68. Calderon $M A$, A lves $B$, Jacobson $M$, et al. Allergen injection immunotherapy for seasonal allergic rhinitis. Cochrane $D$ atabase Syst Rev 2007;1:CD 001936.

69. A bramson M J, Puy R M , W einer J M . A llergen immunotherapy for asthma. Cochrane Database Syst R ev 2003;4:CD 001186.

\section{ABOUT THE AUTHORS}

\section{Ashok K Gupta (Corresponding Author)}

Professor and Head, Department of Otolaryngology and Head and Neck Surgery (U nit II), Postgraduate Institute of M edical Education and Research, Chandigarh, India, Phone: +91-9814198850 e-mail: drashokpgi@ hotmail.com

\section{Nishit Shah}

Senior Consultant, D epartment of Otolaryngology and H ead and N eck Surgery, B ombay Hospital, M umbai, M aharashtra, India

\section{Mohan Kameswaran}

Director and Senior Consultant, D epartment of Otolaryngology and Head and N eck Surgery, M adras ENT R esearch Foundation, Chennai Tamil Nadu, India 


\section{Davinder Rai}

Senior C onsultant and V ice C hairman, D epartment of O tolaryngology Sir Gangaram Hospital, N ew Delhi, India

\section{TN Janakiram}

Consultant, Department of Otolaryngology and Head and Neck Surgery, Royal Pearl Hospital, Trichy, Tamil Nadu, India

\section{Hemant Chopra}

Professor and Head, Department of Otolaryngology, Dayanand M edical College, L udhiana, Punjab, India

\section{Ravi Nayar}

Professor and Head, Department of Otolaryngology and Head and Neck Surgery, St J ohn's Hospital, B engaluru, Karnataka, India

\section{Arvind Soni}

Senior Consul tant, Department of Otolaryngology and H ead and N eck Surgery, A pollo Hospitals, New Delhi, India

\section{NK Mohindroo}

Professor and Head, Department of Otolaryngology and Head and Neck Surgery, Indra Gandhi M edical College, Shimla, Himachal Pradesh, India

\section{Madhu Sudana Rao}

Consultant, Department of Otolaryngology and Head and Neck Surgery, M adhumani Nursing H ome, Nandyal, A ndhra Pradesh, India

\section{Sandeep Bansal}

Assistant Professor, Department of Otolaryngology and Head and Neck Surgery, Postgraduate Institute of M edical Education and Research, Chandigarh, India

\section{KR Meghnadh}

Head, Department of ENT, M A A ENT H ospital, Hyderabad, A ndhra Pradesh, India

\section{Neelam Vaid}

Associate Professor, Department of Otolaryngology, KEM Hospital Pune, M aharashtra, India

\section{Hetal Marfatia Patel}

A ssociate Professor, Department of Otolaryngology, KEM Hospital Pune, M aharashtra, India

\section{Sanjay Sood}

Consultant, Department of ENT, Holy Family Hospital, New Delhi India

\section{Sunita Kanojia}

Clinical A ssistant, Department of O tolaryngology, B ombay Hospital M umbai, M aharashtra, India

\section{Kshitij Charaya}

Senior Resident, Department of Otolaryngology and H ead and Neck Surgery, Postgraduate Institute of M edical Education and Research Chandigarh, India

\section{SC Pandhi}

Former C onsultant, Department of O tolaryngology and Head and N eck Surgery, Postgraduate Institute of M edical Education and R esearch Chandigarh, India

\section{SBS Mann}

Former Director, Government Medical College and Hospital Chandigarh, Former H ead, D epartment of Otolaryngology and Head and Neck Surgery, Postgraduate Institute of M edical Education and Research, Chandigarh, Director-Principal, Miri Piri Institute of M edical Sciences and R esearch, Shahabad M arkanda, H aryana, India 